\title{
Optimal Piling Network Corrosion Protection System for Al-Zubair Harbor
}

\author{
Mohammed H. Hafiz, Wisam K. Hamdan, Ruaa Kaream Salman \\ Department of Production and Metallurgy Engineering, University of Technology, Baghdad, Iraq. \\ Email: drmhh1962@gmail.com
}

Received August 13 ${ }^{\text {th }}, 2012$; revised September $17^{\text {th }}, 2012$; accepted October $2^{\text {nd }}, 2012$

\begin{abstract}
Cathodic protection is an effective electrochemical technique for preventing corrosion of metallic structures, for large structures like piles network impressed current cathodic protection (ICCP) system is usually preferred. The main aim of this study is to obtain the optimum protection potential that would provide a full cathodic protection for steel piles network immersed in sea water at Al-Zubair harbor. The effect of one immeasurable factor (path of anode $\left(\chi_{1}\right)$ ) and two measurable factors (position of anode $\left(\chi_{2}\right)$ and voltage of power supply $\left(\chi_{3}\right)$ ) on protection potential are studied. Each factor has three different levels (high, medium, and low). Twenty-seven experiments were conducted based on a full factorial design of experiments. The results show that, a sufficient protection for three cathodes can be provided through the electrical circuit connecting them within the appropriate geometric shape. The protection potential is increased with increasing the voltage of power supply and decreasing of distance between the anode and cathodes (piles network).
\end{abstract}

Keywords: Impressed Current Cathodic Protection; Piles Network; Path of Anode; Position of Anode; Optimal Combination

\section{Introduction}

Al-Zubair harbor is one of the most important harbors in Iraq. Preventing the destruction of steel harbor structures has huge benefit of Iraqi economy; the common form of the destruction in steel harbor structures is corrosion. Corrosion can be defined as a destructive attack for a metal by a chemical or electrochemical reaction with its environment, cathodic protection is probably the most important method of corrosion control [1,2]. The harsh environment of Al-Zubair of the salt water, salt laden moisture and high temperature fluctuation with the marine growth on the marine structures create a challenging to protection and maintenance processes for steel pipe piles located in a marine environment for large structures like piles network cathodic protection is usually preferred. There are two types of cathodic protection systems, the first type uses metals which are more reactive than the metal to be protected from corrosion, and this is called a galvanic or sacrificial cathodic protection system [3]. The second type of cathodic protection involves the use of a direct current power source and auxiliary anodes which is called an impressed current cathodic protection system [4]. The two mentioned methods require the identification of the polarization parameters (current density and potential) [5]. In this work impressed current cathodic protection system is used. There are many factors influencing the polarization parameters in cathodic pro- tection. The present work deals with steel piles network for marine use which are support structures in harbors in seawater and rivers. The process of determining the path and position of the anode in a wide area defined by piles is a complex process because of an unspecified number of sites. In order to limit the number of possibilities, triangular area has been studied in the form of a right angled triangle. In spite of this simplification; the subject was still complex because of the wide possibilities for the site of anode through triangular region. For this reason; three peripheral paths (sides of triangle) are suggested to study the effect of position of anode on these paths. The unit of piles network which consists of three piles placed in the corners of right-angled triangle is shown in Figure 1. So the suggested factors in this work are: path of anode, position of anode, and voltage of power supply, each factor has been studied based on three levels for each one. Full factorial design is a design of experimental method which is used in this work, factorial experiments include all possible factor-level combinations in the experimental design; therefore, the factorial experiments can be conducted in a wide variety of experimental designs [6].

\section{Aim of This Work}

The aim of this work is to find the optimum path and position of the anode and voltage of power supply which 


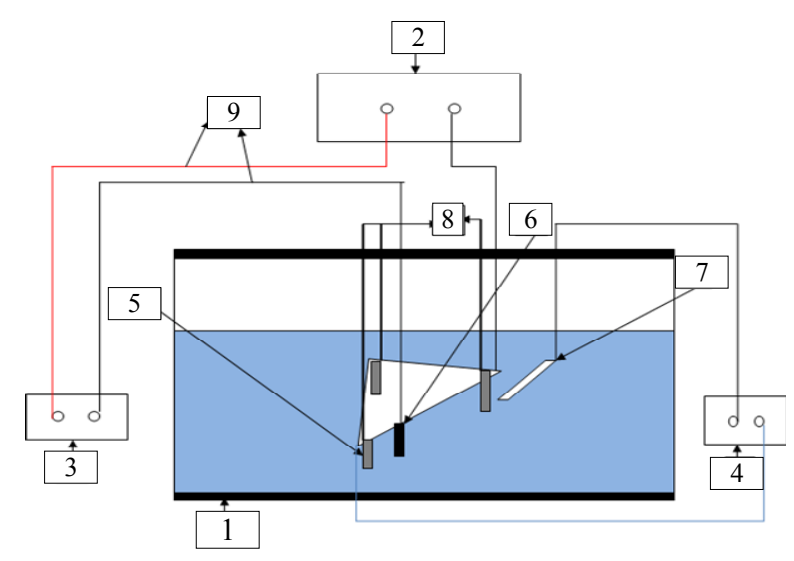

Figure 1. Schematic representation of the proposed impressed current cathodic protection system.

produces a full protection with optimum protection potential value

\section{Experimental Work}

\subsection{Materials}

The material used in this work is low carbon steel which is used in marine stricture of AL-Zubair harbor, the auxiliary electrode was highly pure graphite rod of $6 \mathrm{~mm}$ diameter and $10 \mathrm{~mm}$ length.

\subsection{Experimental Setup}

The experimental work includes the cathode electrode preparation for potentiostate tests and impressed current cathodic protection system and includes the solution preparation. The details of experimental setup are explained in "Rua'a A. Salman [7]".

\subsection{Cathodic Protection}

The process of determining the site of the anode in a wide area defined by piles is a complex process because of an unspecified number of sites. In order to limit the number of possibilities, triangular area has been studied in the form of a right angled triangle. In spite of this simplification the subject was still complex because of the wide possibilities for the site of anode through triangular region. For this reason; three peripheral paths are suggested to study the effect of peripheral sites on these paths and then take advantage of this study to predict the impact of sites within the triangular region. The unit of piles network which consists of three piles placed in the corners of right-angled triangle is shown in Figure 2. The details of the movement of anode are explained in "Rua'a A. Salman [7]".

\subsection{Full Factorial Design}

A design in which every setting of every factor appears

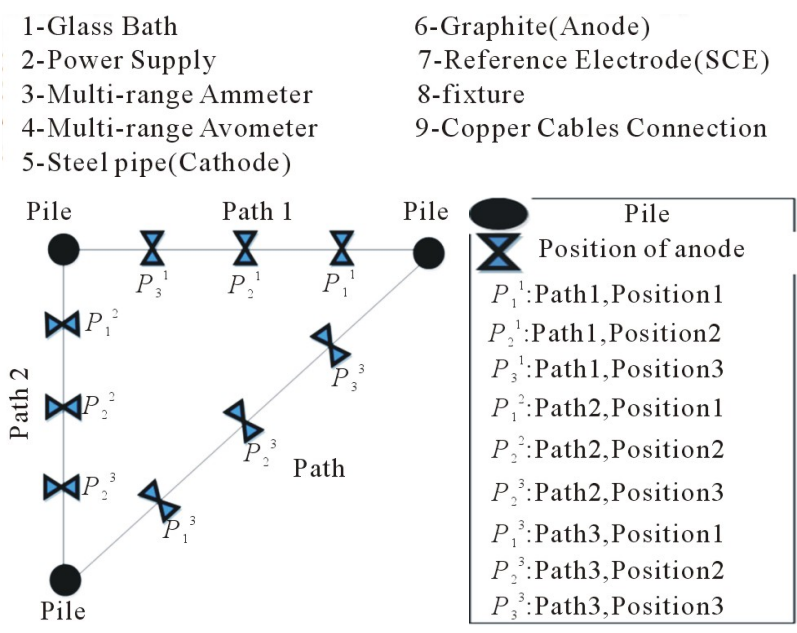

Figure 2. Unit of piles network consisting of three piles arranged as a right-angled triangle.

with every setting of every other factor is a full factorial design [8]. Factorial experiments include all possible factors-level combinations in the experimental design; therefore, the factorial experiments can be conducted in a wide variety of experimental designs [9]. In this work, the proposed independent variables are three, the path of anode, position of anode, and voltage of power supply. Each one of these variables has three levels, high, middle, and low or $-1,0,+1$ for the path of anode (path 1, path 2 , and path 3$)$,position of anode $(1.8,3.7$, and 5.6) for path 1 and path 2 while at path3(2.6, 5.3, and 7.9), voltage of power supply $(1.5,2$, and 2.5$)$. The three-level design is written as a $3^{k}$ factorial design, it means that $k$ factors are considered each of the 3 levels. In this model, there would be 27 experiments and it is shown in Table 1.

\section{Results and Discussion}

\subsection{Potentiostat Test Results}

Polarization was carried out to measure the corrosion current density $\left(\mathrm{i}_{\text {corr }}\right)$ and corrosion potential $\left(\mathrm{E}_{\text {corr }}\right)$ for carbon steel in 3\% $\mathrm{NaCl}$ solution. Figure 3 illustrates the corrosion behavior of specimen of carbon steel polarized in $3 \% \mathrm{NaCl}$ solution. The polarization curve shows cathodic and anodic regions, from the figure $\mathrm{i}_{\text {corr }}$ and $\mathrm{E}_{\text {corr }}$ are identified. Table 2 shows $\mathrm{i}_{\text {corr }}$ and $\mathrm{E}_{\text {corr }}$ for the specimen.

\subsection{Cathodic Polarization Protection}

The potential was measured every 5 minutes during 300 minutes of an experiment. Table 3 shows the output of the experiments. Figures 4-12 represent the relationship between potential and time for various path of anode, position of anode, and voltage of power supply. The protection potential of steel pipe when using saturated calomel electrode is $-800 \mathrm{mV}$ [10]. Protection potential in 
Table 1. The layout of the 27 experiment based on a full factorial design of experiment.

\begin{tabular}{|c|c|c|c|c|c|c|}
\hline \multicolumn{4}{|c|}{ Coded Value } & \multicolumn{3}{|c|}{ Original Value } \\
\hline No. & $\chi_{1}$ & $\chi_{2}$ & $\chi_{3}$ & Path of anode & $\begin{array}{c}\text { Position } \\
\text { of anode }(\mathrm{cm})\end{array}$ & $\begin{array}{c}\text { Voltage of power } \\
\text { supply (V) }\end{array}$ \\
\hline 1 & -1 & -1 & -1 & Path 1 & 1.8 & 1.5 \\
\hline 2 & 0 & -1 & -1 & Path 2 & 1.8 & 1.5 \\
\hline 3 & 1 & -1 & -1 & Path 3 & 2.6 & 1.5 \\
\hline 4 & -1 & 0 & -1 & Path 1 & 3.7 & 1.5 \\
\hline 5 & 0 & 0 & -1 & Path 2 & 3.7 & 1.5 \\
\hline 6 & 1 & 0 & -1 & Path 3 & 5.3 & 1.5 \\
\hline 7 & -1 & 1 & -1 & Path 1 & 5.7 & 1.5 \\
\hline 8 & 0 & 1 & -1 & Path 2 & 5.7 & 1.5 \\
\hline 9 & 1 & 1 & -1 & Path 3 & 7.9 & 1.5 \\
\hline 10 & -1 & -1 & 0 & Path 1 & 1.8 & 2 \\
\hline 11 & 0 & -1 & 0 & Path 2 & 1.8 & 2 \\
\hline 12 & 1 & -1 & 0 & Path 3 & 2.6 & 2 \\
\hline 13 & -1 & 0 & 0 & Path 1 & 3.7 & 2 \\
\hline 14 & 0 & 0 & 0 & Path 2 & 3.7 & 2 \\
\hline 15 & 1 & 0 & 0 & Path 3 & 5.3 & 2 \\
\hline 16 & -1 & 1 & 0 & Path 1 & 5.7 & 2 \\
\hline 17 & 0 & 1 & 0 & Path 2 & 5.7 & 2 \\
\hline 18 & 1 & 1 & 0 & Path 3 & 7.9 & 2 \\
\hline 19 & -1 & -1 & 1 & Path1 & 1.8 & 2.5 \\
\hline 20 & 0 & -1 & 1 & Path 2 & 1.8 & 2.5 \\
\hline 21 & 1 & -1 & 1 & Path 3 & 2.6 & 2.5 \\
\hline 22 & -1 & 0 & 1 & Path 1 & 3.7 & 2.5 \\
\hline 23 & 0 & 0 & 1 & Path 2 & 3.7 & 2.5 \\
\hline 24 & 1 & 0 & 1 & Path 3 & 5.3 & 2.5 \\
\hline 25 & -1 & 1 & 1 & Path 1 & 5.7 & 2.5 \\
\hline 26 & 0 & 1 & 1 & Path 2 & 5.7 & 2.5 \\
\hline 27 & 1 & 1 & 1 & Path 3 & 7.9 & 2.5 \\
\hline
\end{tabular}

Table 2. Potentiostat test results.

\begin{tabular}{cccc}
\hline $\mathrm{I}_{\text {corr }}\left(\mu \mathrm{A} / \mathrm{cm}^{2}\right)$ & $\mathrm{E}_{\text {corr }}(\mathrm{mV})$ & Alloy & NaCl\% concentration \\
\hline 291.4 & -468.4 & Low Carbon Steel & 3 \\
\hline
\end{tabular}


Table 3. Complete response table for 27 experiment based on full factorial design.

\begin{tabular}{|c|c|c|c|c|c|c|c|}
\hline \multirow[b]{2}{*}{ Potential protected $(-\mathrm{mV})$} & \multicolumn{3}{|c|}{ Original Value } & \multicolumn{4}{|c|}{ Coded Value } \\
\hline & $\begin{array}{l}\text { Voltage of power } \\
\text { supply (V) }\end{array}$ & $\begin{array}{l}\text { Position } \\
\text { of anode }\end{array}$ & Paths of anode & $\chi_{3}$ & $\chi_{2}$ & $\chi_{1}$ & No. \\
\hline 644 & 1.5 & 1.8 & Path 1 & -1 & -1 & -1 & 1 \\
\hline 686 & 1.5 & 1.8 & Path 2 & -1 & -1 & 0 & 2 \\
\hline 649 & 1.5 & 2.6 & Path 3 & -1 & -1 & 1 & 3 \\
\hline 671 & 1.5 & 3.7 & Path 1 & -1 & 0 & -1 & 4 \\
\hline 676 & 1.5 & 3.7 & Path 2 & -1 & 0 & 0 & 5 \\
\hline 654 & 1.5 & 5.3 & Path 3 & -1 & 0 & 1 & 6 \\
\hline 690 & 1.5 & 5.7 & Path 1 & -1 & 1 & -1 & 7 \\
\hline 651 & 1.5 & 5.7 & Path 2 & -1 & 1 & 0 & 8 \\
\hline 648 & 1.5 & 7.9 & Path 3 & -1 & 1 & 1 & 9 \\
\hline 796 & 2 & 1.8 & Path 1 & 0 & -1 & -1 & 10 \\
\hline 854 & 2 & 1.8 & Path 2 & 0 & -1 & 0 & 11 \\
\hline 793 & 2 & 2.6 & Path 3 & 0 & -1 & 1 & 12 \\
\hline 816 & 2 & 3.7 & Path 1 & 0 & 0 & -1 & 13 \\
\hline 825 & 2 & 3.7 & Path 2 & 0 & 0 & 0 & 14 \\
\hline 798 & 2 & 5.3 & Path 3 & 0 & 0 & 1 & 15 \\
\hline 850 & 2 & 5.7 & Path 1 & 0 & 1 & -1 & 16 \\
\hline 794 & 2 & 5.7 & Path 2 & 0 & 1 & 0 & 17 \\
\hline 791 & 2 & 7.9 & Path 3 & 0 & 1 & 1 & 18 \\
\hline 1019 & 2.5 & 1.8 & Path1 & 1 & -1 & -1 & 19 \\
\hline 1096 & 2.5 & 1.8 & Path 2 & 1 & -1 & 0 & 20 \\
\hline 978 & 2.5 & 2.6 & Path 3 & 1 & -1 & 1 & 21 \\
\hline 1041 & 2.5 & 3.7 & Path 1 & 1 & 0 & -1 & 22 \\
\hline 1050 & 2.5 & 3.7 & Path 2 & 1 & 0 & 0 & 23 \\
\hline 988 & 2.5 & 5.3 & Path 3 & 1 & 0 & 1 & 24 \\
\hline 1091 & 2.5 & 5.7 & Path 1 & 1 & 1 & -1 & 25 \\
\hline 1011 & 2.5 & 5.7 & Path 2 & 1 & 1 & 0 & 26 \\
\hline 981 & 2.5 & 7.9 & Path 3 & 1 & 1 & 1 & 27 \\
\hline
\end{tabular}




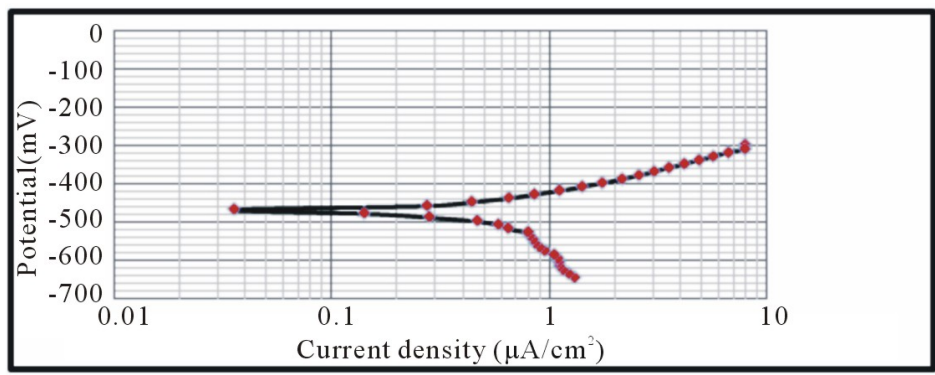

Figure 3. Potentiostat test for specimen of carbon steel in $3 \% \mathrm{NaCl}$ solution.

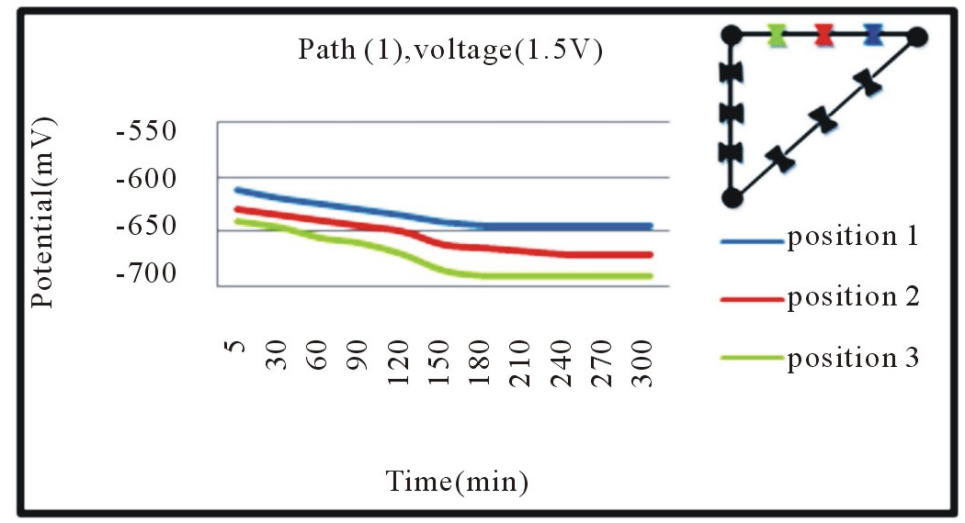

Figure 4. Potential vs. time for first path of anode and (1.5) voltage of power supply with different positions of anode.

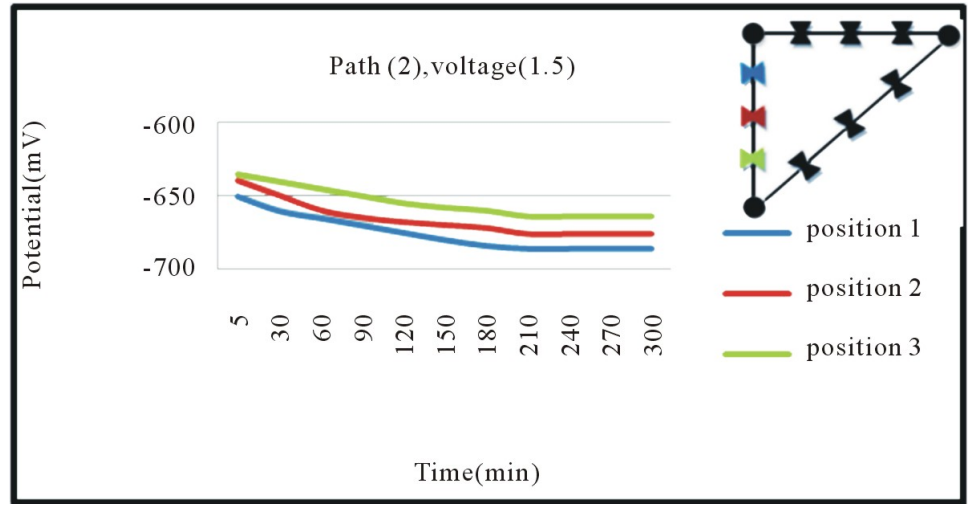

Figure 5. Potential vs. time for second path of anode and (1.5) voltage of power supply with different positions of anode.

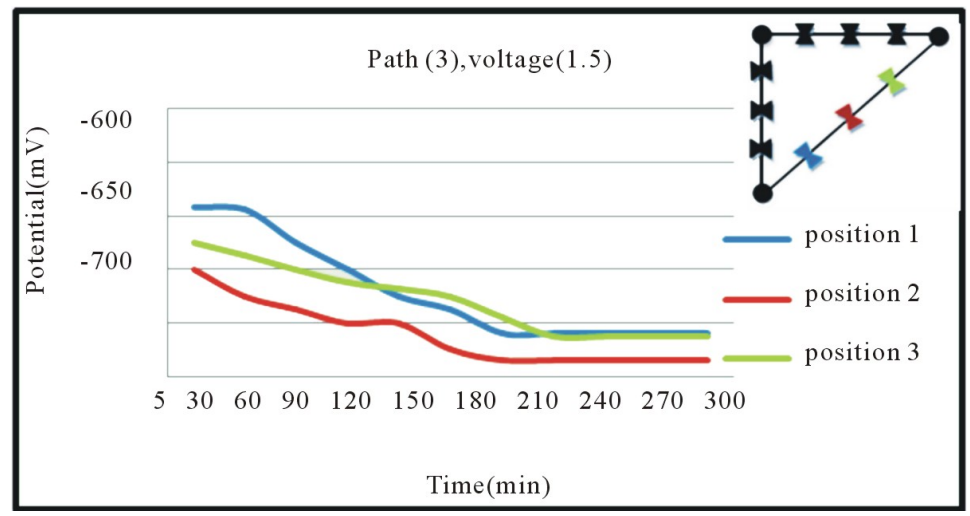

Figure 6. Potential vs. time for third path of anode and (1.5) voltage of power supply with different positions of anode. 


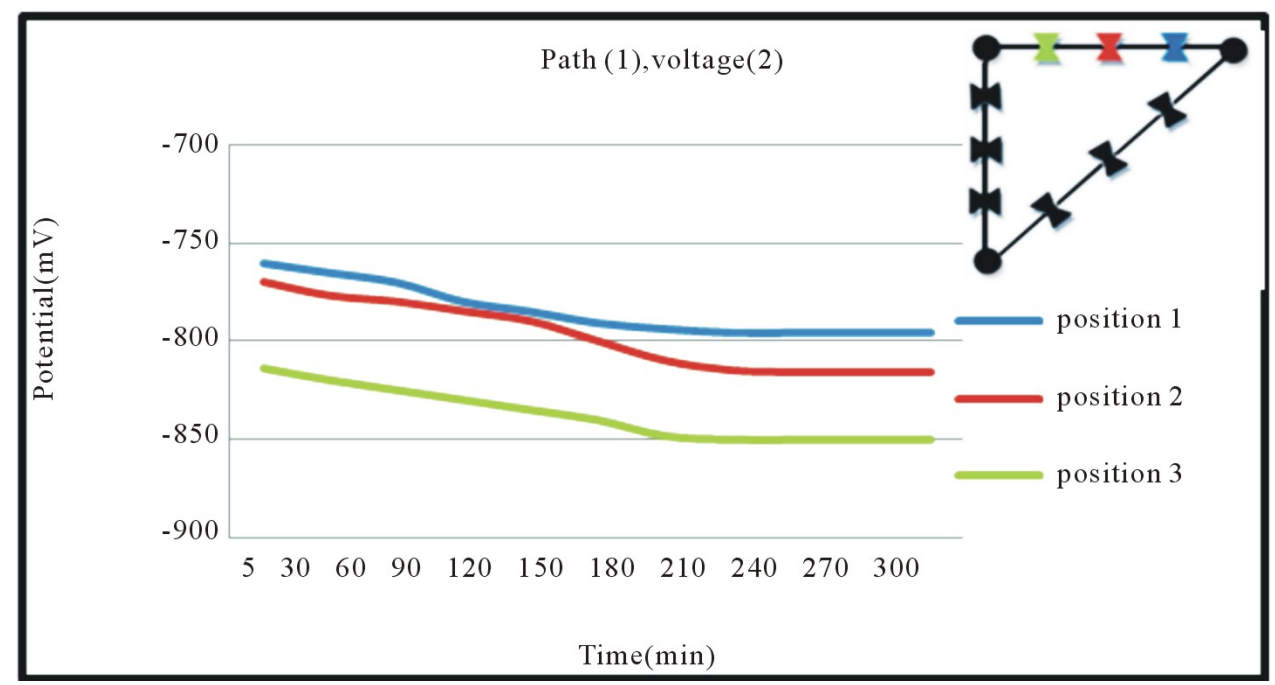

Figure 7. Potential vs. time for first path of anode and (2) voltage of power supply with different positions of anode.

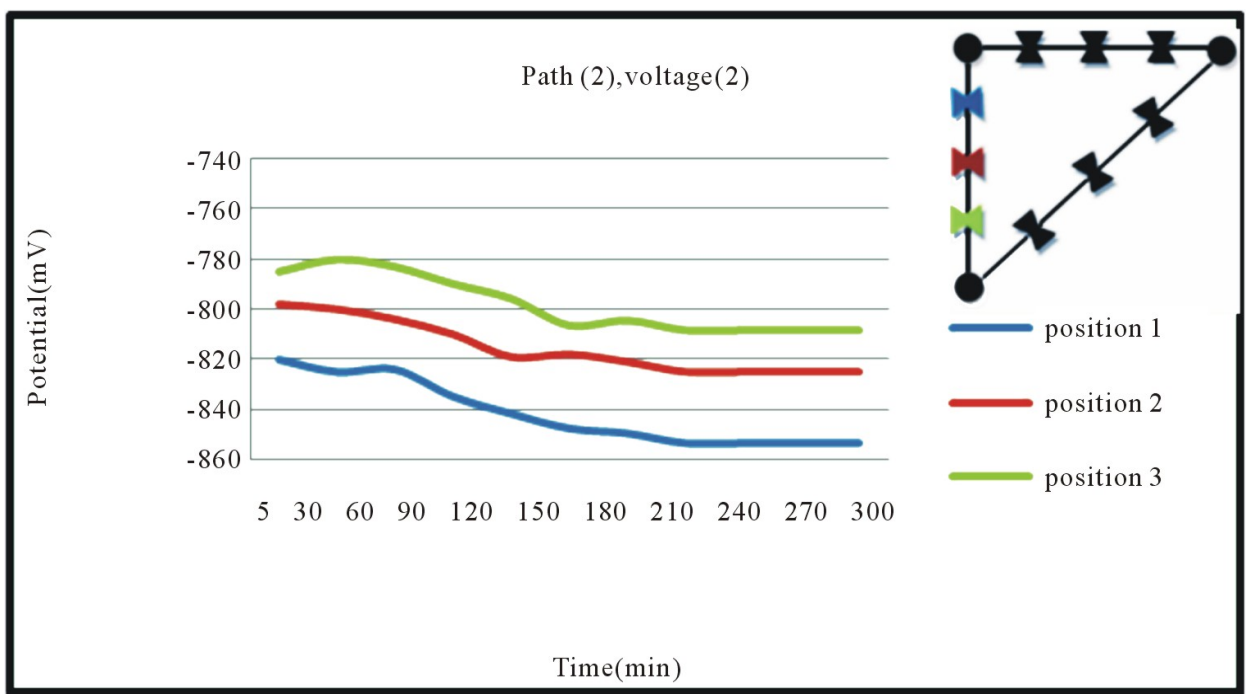

Figure 8. Potential vs. time for second path of anode and (2) voltage of power supply with different positions of anode.

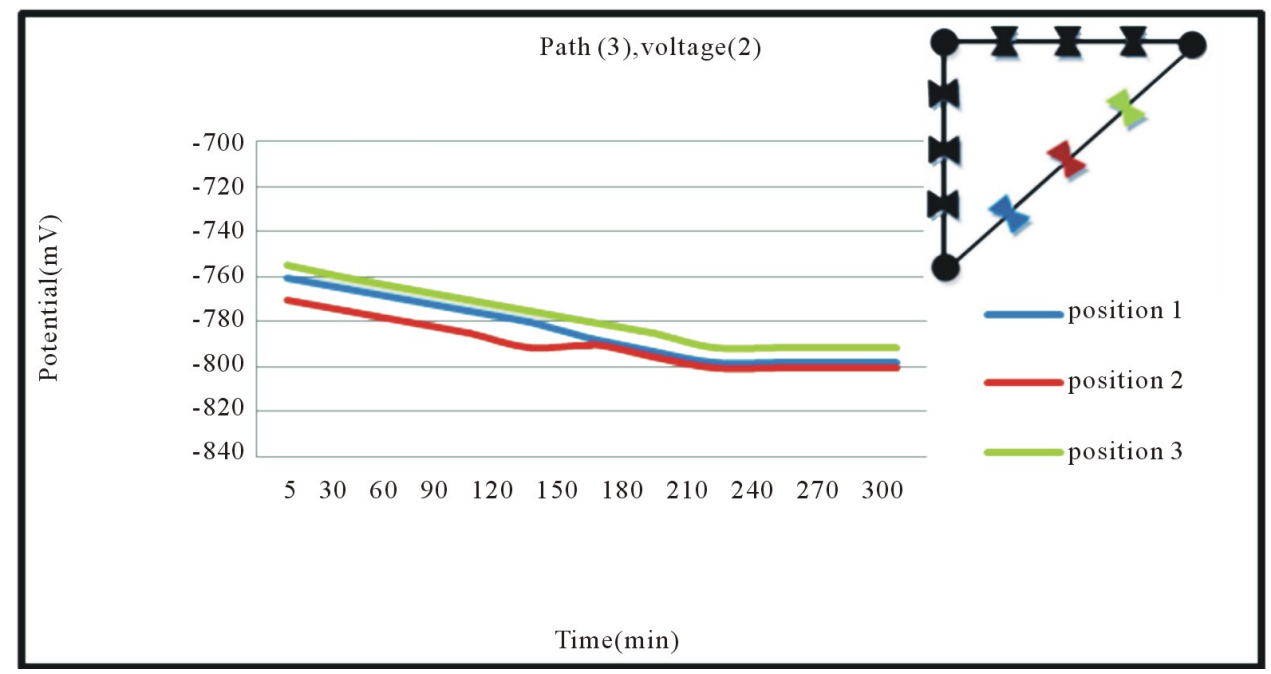

Figure 9. Potential vs. time for third path of anode and (2) voltage of power supply with different positions of anode. 


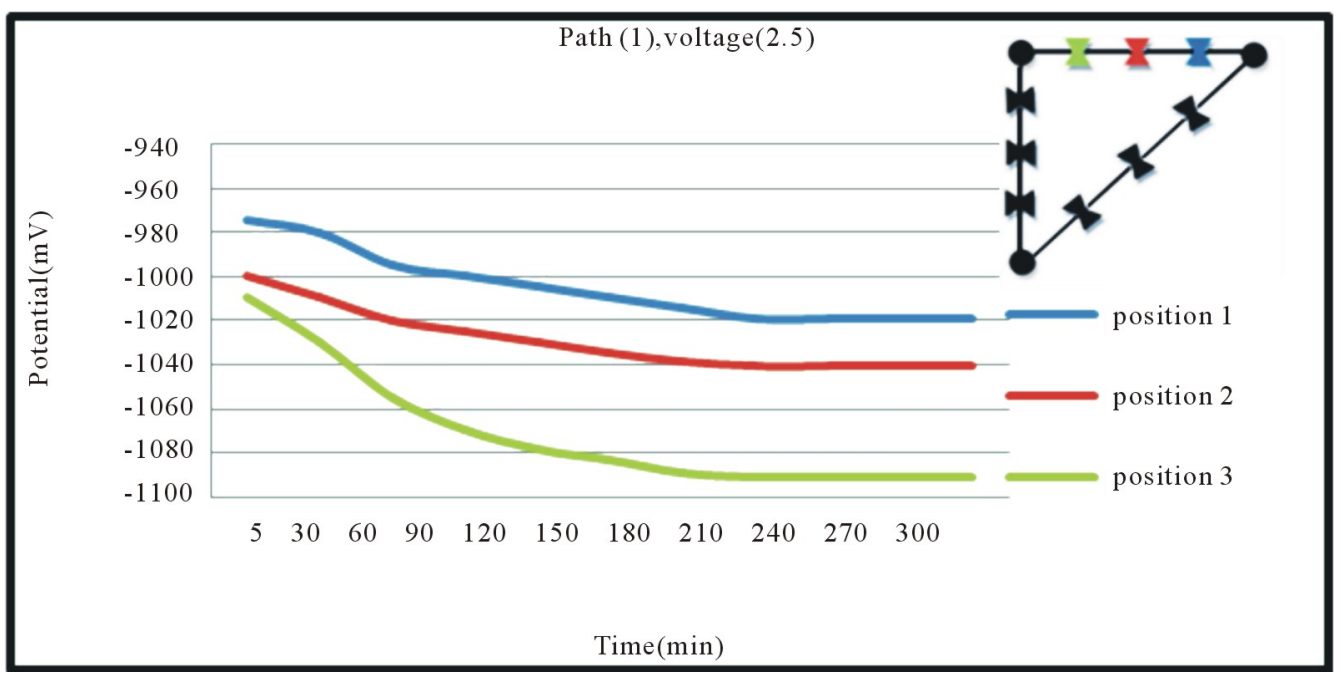

Figure 10. Potential vs. time for first path of anode and (2.5) voltage of power supply with different positions of anode.

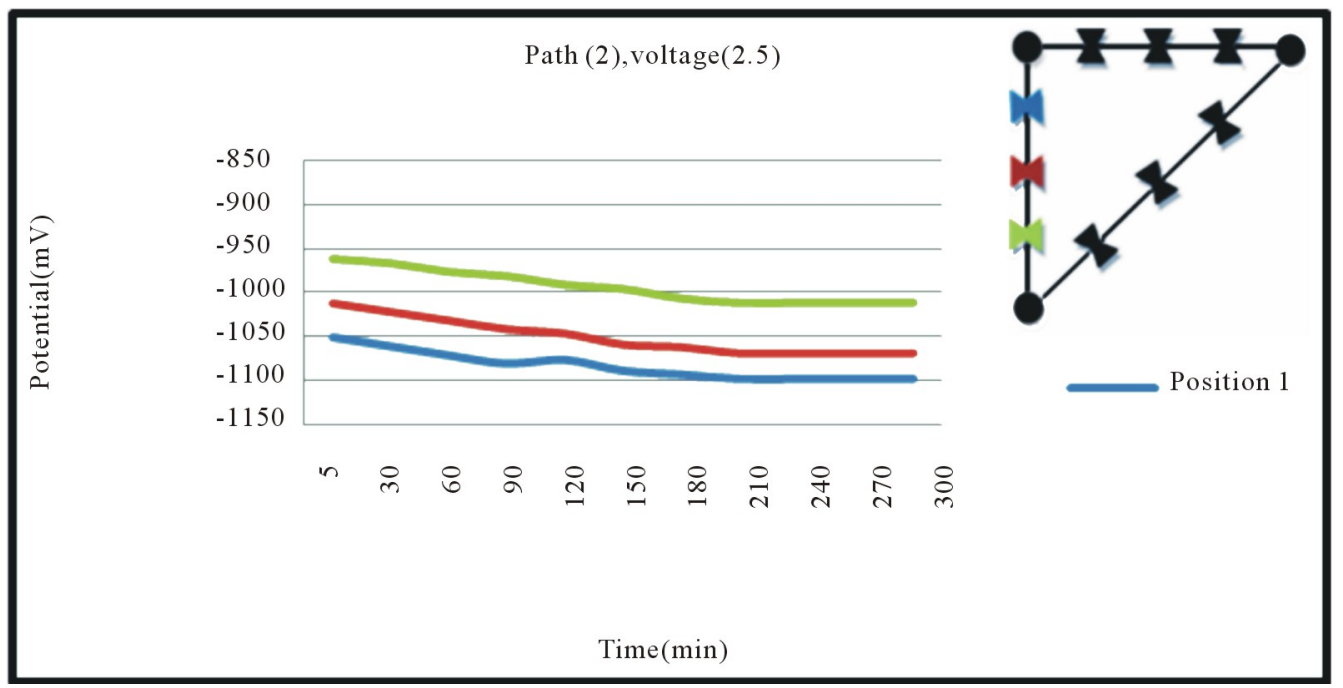

Figure 11. Potential vs. time for second path of anode and (2.5) voltage of power supply with different positions of anode.

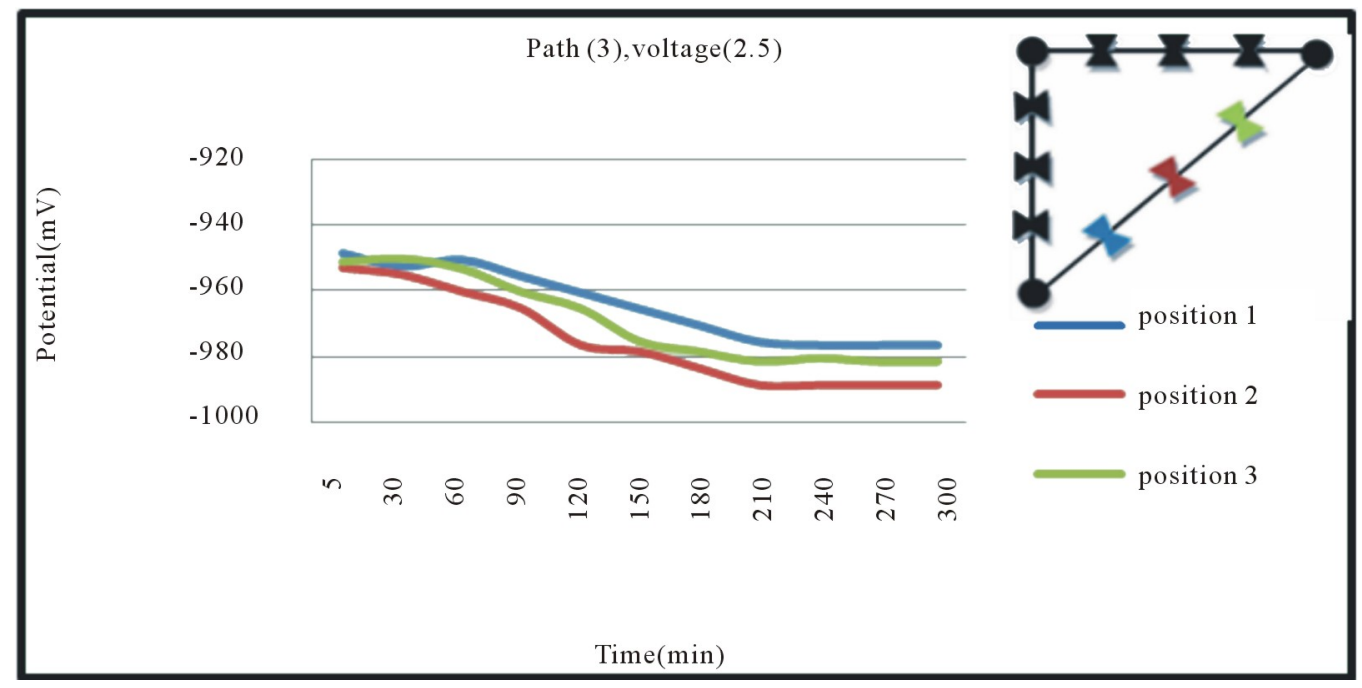

Figure 12. Potential vs. time for third path of anode and (2.5) voltage of power supply with different positions of anode. 
Figures 4-6 is more than $-800 \mathrm{mV}$ at different paths and positions of anode with 1.5 voltage of power supply; therefore, the selected voltage of power supply does not protect the steel piles because their potential is more than the desired value. In Figure 7, the voltage of power supply is $2 \mathrm{~V}$ and the anode is set on the first path, when the anode place is in the first position, the distance between the anode and the piles equals to $17 \mathrm{~cm}$ and the value of protection potential is $-796 \mathrm{mV}$. In position (2) the distance between the anode and the piles is equal to $16 \mathrm{~cm}$ and the protection potential is $-816 \mathrm{mV}$. At position (3) the distance between the anode and the piles equals 15 $\mathrm{cm}$ and protection potential is $-850 \mathrm{mV}$. There is an inverse relationship between protection potential and the distance between the anode and cathodes, this relationship is given by the following Equation [10]:

$$
V=0.171 \rho I / D
$$

where $V$ represents the potential, $\rho$ is the resistivity of environment, $I$ represent current density, and $D$ is the distance between the cathode and anode; therefore, when the distance between the anode and piles is reduced, this will lead to a reduction in protection potential to less than $-800 \mathrm{mV}$. In Figure 8 voltage of power supply is $2 \mathrm{~V}$ and the anode is set on the second path, at position (1) and (2) protection potential is less than $-800 \mathrm{mV}$ while at position (3) protection potential is more than $-800 \mathrm{mV}$. The distance between the anode and the piles in the first position equals $15 \mathrm{~cm}$ and protection potential is $-854 \mathrm{mV}$. The distance between the anode and the piles in the second position equals $16 \mathrm{~cm}$ and protection potential is $-825 \mathrm{mV}$, in position (3) the distance between the anode and the piles is equal to $17 \mathrm{~cm}$ and the protection potential is $-794 \mathrm{mV}$. These results verify the inverse relationship between protection potential and the distance between the anode and cathodes. In Figure 9, voltage of power supply is $2 \mathrm{~V}$ and the anode is set at the third path, at this path the protection potential is more than -800 $\mathrm{mV}$ for all positions of anode. This path is represented hypotenuse in the right-angled triangle so the length of this path is $10.6 \mathrm{~cm}$ longer than the first and second paths, which the length of each one of them equals $7.5 \mathrm{~cm}$. The distance between the anode and the piles in position (1) is $16.6 \mathrm{~cm}$ and protection potential is $-793 \mathrm{mV}$, in position (2) the distance between the anode and the piles is $16.4 \mathrm{~cm}$ and protection potential is $-798 \mathrm{mV}$, in position (3) the distance between the anode and the piles is equal to $16.6 \mathrm{~cm}$ and the protection potential is $-791 \mathrm{mV}$. As previously stated, when the distance between the anode and piles is reduced, it will lead to increase in protection potential in a negative direction. The protection potential in Figures 10-12 is less than $-800 \mathrm{mV}$ at all paths and positions of anode with 2.5 voltage of power supply; therefore, the selected voltage of power supply protects the steel piles at all paths and positions of anode because the protection potential is less than $-800 \mathrm{mV}$. In Figure 10, voltage of power supply is $2.5 \mathrm{~V}$ and the anode is set on the first path. When the anode is in the first position, the distance between the anode and the piles is equal to $17 \mathrm{~cm}$ and protection potential is $-1019 \mathrm{mV}$, in the second position the distance between the anode and the piles is $16 \mathrm{~cm}$ and protection potential is $-1041 \mathrm{mV}$, at position (3) the distance between the anode and the piles is $15 \mathrm{~cm}$ and protection potential is $-1091 \mathrm{mV}$. It can be observed that protection potential is increased in negative direction when the distance between the anode and cathodes is decreased. In Figure 11, voltage of power supply is $2.5 \mathrm{~V}$ and the anode is set at the second path, the distance among the anode and the piles in position (1) is 15 $\mathrm{cm}$ and protection potential is $-1096 \mathrm{mV}$, the distance among the anode and the piles in position (2) is $16 \mathrm{~cm}$ and protection potential is $-1050 \mathrm{mV}$, in position (3) the distance among the anode and the piles is equal to $17 \mathrm{~cm}$ and the protection potential is $-1011 \mathrm{mV}$. In Figure 12, voltage of power supply is $2.5 \mathrm{~V}$ and the anode is set on the third path, it can be observed that the protection potential at this path is less negative than protection potential at the first and second path because the length of this path is larger than the first and second path. The distance between the anode and the piles in position (1) is $16.6 \mathrm{~cm}$ and protection potential is $-978 \mathrm{mV}$, the distance between the anode and the piles in position (2) is $16.4 \mathrm{~cm}$ and protection potential is $-988 \mathrm{mV}$, in position (3) the distance between the anode and the piles is equal to 16.6 $\mathrm{cm}$ and the protection potential is $-981 \mathrm{mV}$.

\section{Conclusions}

1) Full factorial design is a powerful tool to obtain accurate results about the influence of the factors and their interactions by using experiments including all possible factors-level combinations in the experimental design.

2) Full protection for three cathodes can be provided through an electrical circuit connecting them within an appropriate geometric shape.

3) When the distance between the anode and piles are reduced, this will lead to increase in the protection potential in a negative direction.

4) When the distance between the anode and piles are reduced, this will lead to increase in the protection potential in negative direction.

It can be noticed that the protection potential at third path is less than the other paths because the third path (hypotenuse in the right-angled triangle) is the longest path among the others.

\section{REFERENCES}

[1] West Virginia University, "Appalachian Underground Corrosion Short Course," MATCOR, Inc., Morgantown, 
2009.

[2] R. W. Revie and H. H. Uhlig, "Corrosion and Corrosion Control: An Introduction to Corrosion Science and Engineering," 4th Edition, John Wiley \& Sons, Hoboken, 2008. doi:10.1002/9780470277270

[3] M. Al-Otaibi, "The Application of Beasy Software to Simulate Cathodic Protection of Pipelines and Storage Tanks," M.Sc. Thesis, The University of British Columbia, Vancouver, 2010.

[4] Y. M. Abdu Al-Sahib, "The Use of Al-Zn Alloys as Sacrificial Anodes to Protect Buried Steel Pipes," M.Sc. Thesis, University of Technology, Baghdad, 2010.

[5] G. A. Ali, "Identification of Polarization Parameters for Cathodic Protection By Using Neural Network," M.Sc. Thesis, University of Technology, Baghdad, 2007.

[6] R. L. Mason, R. F. Gunst and J. L. Hess, "Statistical De- sign and Analysis of Experiments," 2nd Edition, John Wiley \& Sons, Hoboken, 2003. doi:10.1002/0471458503

[7] R. A. Salman, "Optimal Piling Network Corrosion Protection System for AL-Zubair Harbor," M.Sc. Thesis, University of Technology, Baghdad, 2012.

[8] International SEMATECH and International SEMATECH Member Companies, "NIST/SEMATECH e-Handbook of Statistical Methods," 2010. http://www.itl.nist.gov/div898/handbook/

[9] R. L. Mason, R. F. Gunst and J. L. Hess, "Statistical Design and Analysis of Experiments," 2nd Edition, John Wiley \& Sons, Hoboken, 2003. doi:10.1002/0471458503

[10] M. H. Hafiz, "Modeling of Pipeline Corrosion Control by Cathodic Protection," Ph.D. Thesis, University of Technology, Baghdad, 2006. 